Escuela de Ciencias Sociales y Humanidades, UNED, C.R.

URL: http://investiga.uned.ac.cr/revistas/index.php/espiga/index

DOI: http://dx.doi.org/10.22458/re.v16i33.1804

ISSN: 1409-4002 • e-ISSN: 2215-454X

\title{
Historias paralelas: historias de ayer y hoy
}

\section{Patricia Méndez-Guerrero}

Recibido: 29 de abril, 2017 • Aceptado: 20 de mayo, 2017 • Corregido: 25 de mayo, 2017

\section{RESUMEN}

Historias Paralelas es un programa radiofónico, creado como un piloto para la divulgación de contenidos académicos que permiten la observación de hechos actuales desde la perspectiva histórica o de eventos de la historia desde un enfoque de impacto en nuestro presente. La experiencia de trabajo interdisciplinario se convirtió en un proyecto de comunicación del quehacer académico más allá de las aulas universitarias.

Palabras claves: Producción radiofónica, academia, historia, divulgación, comunicación.

Tiempo que dice

De tiempo somos.

Somos sus pies y sus bocas.

Los pies del tiempo caminan en nuestros pies. A la corta o a la larga, ya se sabe, los vientos del tiempo borrarán las huellas. ¿Travesía de la nada, pasos de nadie? Las bocas del tiempo cuentan el viaje.

Eduardo Galeano. Bocas del tiempo ${ }^{1}$

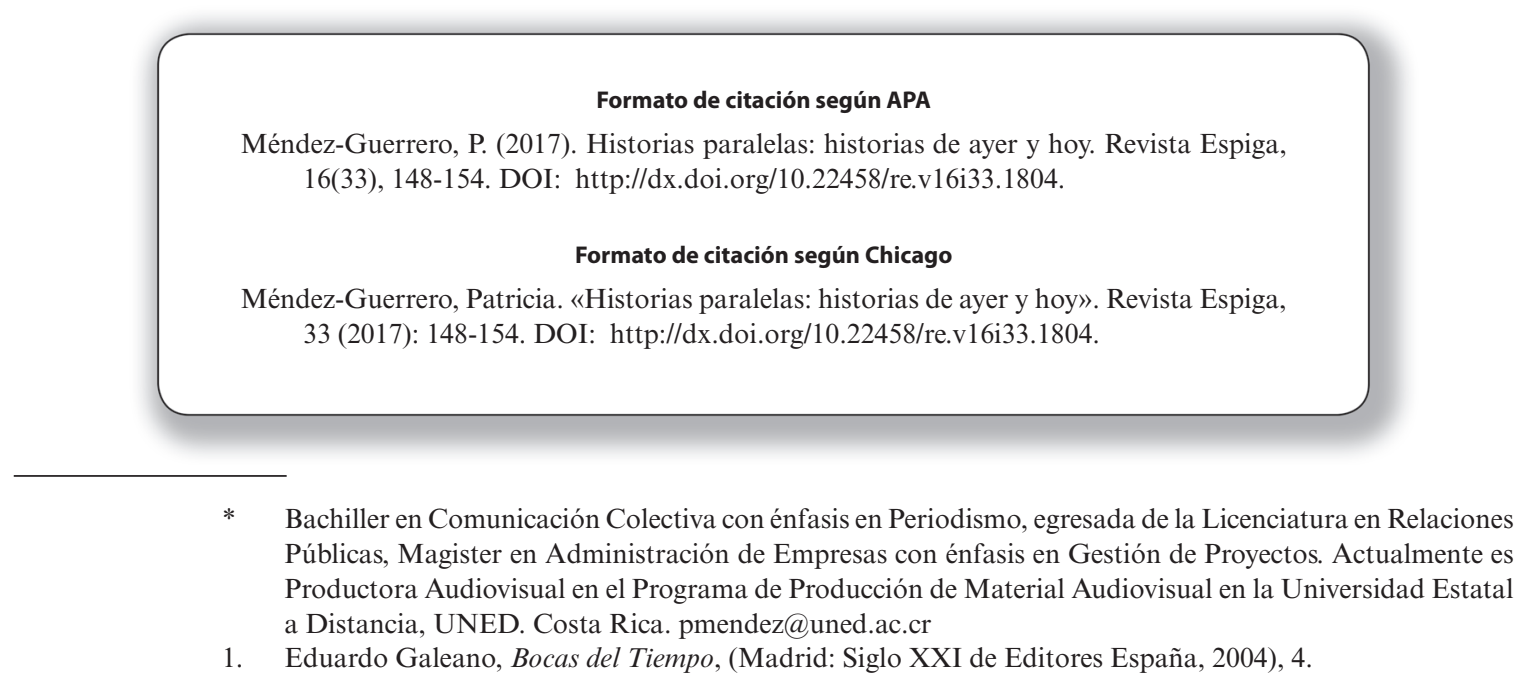




\section{Introducción}

La academia es productora de conocimiento. Desde investigaciones y ensayos elaborados por estudiantes, hasta intrincados proyectos donde participan profesores, catedráticos e investigadores. En ocasiones esos trabajos se quedan en el papel, dentro de las aulas y hasta almacenados en bibliotecas.

La divulgación de esos pensamientos y esas investigaciones fuera de las instituciones de educación superior, puede representar para muchos un reto que raya en lo tortuoso; aun más si se convierte en un proyecto interdisciplinario.

Historias Paralelas, como proyecto de comunicación y proyección de la academia nació de una iniciativa en la que participa la Cátedra de Historia y el Programa de Producción Audiovisual, ambas unidades de trabajo de la Universidad Estatal a Distancia (UNED) que asumieron el reto de formar ese equipo.

Si bien el trabajo académico en la UNED implica en muchas ocasiones la realización de materiales en audio y video de la mano de los profesionales en producción audiovisual, Historias Paralelas proponía no una producción, sino una serie de programas de radio con proyección incluso en medios nacionales.

La inquietud por ese proyecto surgió desde el Encargado de la Cátedra de Historia, Alonso Rodríguez y Patricia Méndez, realizadora del Programa de Producción de Material Audiovisual.

La aventura y el reto profesional y académico iniciaba así.

\section{¿Por qué Historias Paralelas?}

No es el objetivo de este artículo entrar en discusiones teóricas de si la Historia es lineal o cíclica. No obstante, como parte del razonamiento para formular los objetivos del programa se partió de la idea de que para entender el presente era necesario buscar en el pasado y para formular respuestas a problemas de hoy, era conveniente conocer eventos ya superados.

En ocasiones, los hechos que se presentan en el hoy, pueden encontrar similitudes con incidentes del pasado. De esa manera, se construirían los paralelismos históricos.De igual manera, en el tema de cultura o etnohistoria se podrían encontrar semejanzas con brechas temporales o espaciales que permiten crear Historias Paralelas.

Con esas ideas y formulaciones surgió Historias paralelas como una propuesta para analizar nuestro presente a partir de nuestra historia y de esta manera entrelazar dos y hasta los tres tiempos: pasado y presente... y por qué no, futuro.

Las ideas propuestas como guías para la formulación del proyecto fueron las siguientes:

1. Ofrecer un análisis diferente de hoy y de ayer como sociedad y país. 
2. Analizar de forma sencilla y clara la temática de tal manera que quien escuche el programa pueda comprender los contenidos.

3. Relacionar hechos del pasado y del presente con el fin de entender procesos, relaciones, tradiciones, costumbres, ideologías, etc.

4. Proponer ideas para discusiones, foros, ensayos, investigaciones.

\section{Dando forma a la idea}

Igual que los alfareros con la arcilla luego de delimitar la idea se hizo necesario modelarla. Como producción radiofónica la idea debía concretarse en un determinado formato y con su respectiva estructura.

La fórmula de producción que se propuso fue un programa de radio de aproximadamente 25 minutos dirigido principalmente a los estudiantes de la Cátedra de Historia, pero con un lenguaje abierto y sencillo. Esta característica, además de formar parte del lenguaje radiofónico, permitiría que quien lo escuchara, sin importar si era estudiante de la UNED o no, comprendiera los contenidos y los considerara cercanos a su realidad.

El formato fue la entrevista con un trabajo de preproducción. Esto significa que antes de compartir con los especialistas debía realizarse una breve investigación del tema. A partir de esos contenidos indagados se elaborarían las preguntas, con las cuales el objetivo era contar una historia: antecedentes, desarrollo y perspectivas.

Este trabajo de preproducción permite:

- Definir la temática y las preguntas claves.

- Delimitar el tema y con ello disminuir los riesgos de divagación.

- Concentrar las ideas en un tiempo determinado. Hay que recordar que por ser una producción formulada con el interés de ser parte de una programación radiofónica se circunscribe a una duración establecida Cada entrevista, para desarrollar un tema, se prolonga por aproximadamente 20 minutos. Y esa es «la materia prima» para el programa de 30 minutos.

\section{Historias Paralelas desde la academia}

Al llegar el 2015 y al celebrar una producción de 200 programas, Alonso Rodriguez, Encargado de la Cátedra de Historia describió el sentir del equipo de producción al realizar este proyecto:

Amparados bajo el concepto de academia pública, Historias paralelas nace con la idea de favorecer los espacios de reflexión y reacción constructiva. Dentro de esa lógica, busca que a través del abordaje histórico se concientice sobre los problemas actuales y la importancia de salvaguardar los valores culturales. En términos generales se persigue que desde un contexto académico, se hable de temas vedados e invisibilizados, ayudando a subsanar grandes vacíos y sesgos históricos donde la academia por lo general, no gusta hablar. En razón, se intenta 
hacer profesionales y ciudadanos responsables y con formación integral, que sean capaces de entender que la historia es un quehacer amplio y que sobrepasa la vida de los héroes de estatua y pedestal. Historias paralelas invita a interactuar con otros apoyos didácticos, distintos medios tecnológicos y didácticos disponibles; todo con el fin de enriquecer las experiencias de aprendizaje y que bien ayudan a ampliar los conocimientos ${ }^{1}$

Cabe señalar que Historias Paralelas forma parte de los materiales utilizados cada cuatrimestre para los cursos que se imparten desde la Cátedra de Historia (Historia de Costa Rica, Historia de la Cultura y Acervo Cultural)

Sin embargo, aunque la producción es de la Cátedra de Historia, otras unidades académicas han aprovechado el espacio de divulgación y proyección, tal es el caso de la Cátedra de Teología, el Programa de Gestión Local de la Dirección de Extensión Universitaria, el Instituto de Estudios de Género, el Centro de Investigación en Cultura y Desarrollo, CICDE.

\section{Algunas historias paralelas}

En el año 2012 en la agenda noticiosa nacional surgió la posibilidad de convertir el Estado costarricense en un estado laico. La discusión abrió la posibilidad de discutir cambios en el presente y en el futuro de la sociedad.

Una de las ideas que se movió en los medios de comunicación fue cuestionar las razones por las cuales Costa Rica seguía siendo un estado vinculado a la Iglesia cuando eso ya estaba superado en América.

La producción del programa tomó la decisión de incluir el tema en agenda, pero no para discutir si Costa Rica debía o no ser un Estado laico; sino para entender, desde la historia, cómo el estado costarricense se vinculó con la Iglesia; además, cómo es que esa discusión no era nueva en el país.

Para ello se entrevistó a Francisco Quesada, teólogo y filósofo, tutor de la Cátedra de Teología de la Escuela de Ciencias Sociales y Humanidades de la UNED. El objetivo fue ir más allá de la información en los noticiarios para comprender las razones históricas de esa vinculación Estado-Iglesia. enlaces:

Para escuchar los programas dedicados a este tema puede visitar los siguientes

http://audiovisuales.uned.ac.cr/mediateca/audio/1446/

historias-paralelas-27-2012-relaci\%C3\%B3n-estado-igle

http://audiovisuales.uned.ac.cr/mediateca/audio/1447/

historias-paralelas-28-2012-\%C2\%BFcosta-rica-estado-1

1. «Historias Paralelas ya suman más de 200 programas» Programa de Producción de Material Audiovisual. Acceso el día 29 de abril 2017, http://www.uned.ac.cr/dpmd/audiovisuales/ noticias/477-las-historias-paralelas-ya-suman-mas-de-200-programas 
Tales producciones fueron escuchadas por aproximadamente 2 mil personas solo desde su ubicación en la web.

Otro tema que sirve de ejemplo de la estructuración de Historias Paralelas es el de «Los patronos populares en El Salvador». Durante el Congreso Centroamericano de Historia que se realizó en México en el año 2012 se presentó una ponencia donde se describían los patronos populares que predominaban en la sociedad salvadoreña ${ }^{2}$. La disertación estuvo a cargo del historiador e investigador Antonio García Espada, a quien invitamos al programa.

La ponencia explicaba la presencia de una serie de íconos que son venerados incluso en altares, la mayoría de ellos con propiedades sanadoras y que en vida estuvieron vinculados con medicina natural, magia, brujería o medicina alopática.

Si bien el fenómeno no se presenta de la misma manera que en El Salvador, una figura «paralela» en Costa Rica que podría guardar algún parecido es el doctor Moreno Cañas. La comparación permite al oyente considerar cercano un tema que está fuera de la frontera; además, generar un vínculo empático en las construcciones de fe sin importar la cultura.

Por otra parte, quien no conoce del tema o la figura de Moreno Cañas puede obtener un panorama general del personaje y su paso por la historia de nuestro país.

Este programa se puede escucharlo en el siguiente enlace

http://audiovisuales.uned.ac.cr/mediateca/audio/1466/

historias-paralelas-32-2012-patronos-populares

Desde la plataforma en la web, este programa ha sido ingresado para escucharse 1166 veces.

Estos son tan solo dos ejemplos de los temas tratados. Sin embargo, desde el 2011 que se inició la producción se pueden encontrar temas como los siguientes:

- Extranjero en Costa Rica en el siglo XIX

- Amores prohibidos en la Colonia

- Tuberculosis en Costa Rica

- Leyendas costarricenses

- La Virgen de los Ángeles

- Nacimiento de la masonería en el mundo

- Masonería en Costa Rica

- La moda en la Costa Rica del siglo XIX e inicios del siglo XX

- Corridas de toros y festejos populares

- Las Batallas de Coto: Las batallas olvidadas

2. Antonio García Espada, «Patronos Populares Salvadoreños».Boletín de la Academia Salvadoreña de la Historia3 (2013).Acceso el 29 de abril, 2017, https://www.academia.edu/4603016/Patronos_Populares_Salvadore $\%$ C3\%B1os 
- $\quad$ El legado de Mandela

- Enfermedades emergentes: Ayer y hoy

- El paradigma Sumak Kawsay

- Las historias paralelas de la Navidad

- El quijotesco personaje de Cervantes

La lista es solo un ejemplo de la diversidad temática abordada en el programa. Hay temas con diferencias temporales y espaciales, con caracterización cultural, con enfoque religioso, y hasta con las mitologías populares que acompañan a la sociedad humana.

\section{Distribución de las Historias Paralelas}

Historias paralelas es un material académico. Su público primario corresponde a los estudiantes de la UNED. No obstante, la posibilidad de transmisión en Radio Nacional $(101.5 \mathrm{fm})$ abrió el abanico a un público secundario, es decir, a los oyentes tradicionales de esa emisora.

En cuanto a la distribución propuesta, se puede decir que Historias Paralelas llega a los diferentes públicos por los siguientes canales:

1. El estudiante puede obtenerlo en un disco compacto para cubrir los contenidos del cuatrimestre. En el caso del Centro Universitario en el Centro Penal La Reforma, el material se envía por memoria USB.

2. Cada mes se mantiene una parrilla de programación que permite anunciar, de previo, los temas que se abordarán en esas semanas. El anuncio se emite tanto por correos electrónicos como por Facebook, por medio de la página de Audiovisuales UNED.

3. Si los programas abordan temáticas que corresponden a efemérides, se comparten también en Facebook.

4. Se mantiene una transmisión por Radio Nacional (101.5 fm) los lunes a las 8:30 de la noche

5. Asimismo, Radio 870 UCR transmite el espacio por convenio UNED-UCR, los domingos a las 6 de la tarde

6. Todos los programas están en línea, en la plataforma audiovisuales.uned.ac.cr (Este canal de distribución permite que cualquier persona pueda escucharlo, no importa si es o no estudiante de la UNED o si está en el país o fuera de él).

\section{Perspectivas del proyecto}

Historias Paralelas se convirtió en un proyecto de comunicación y proyección de la Cátedra de Historia de la UNED. Fue un piloto que se ha prolongado durante 6 años.

Ha servido de vitrina a temáticas que se discuten solamente en las aulas o en espacios académicos. Ha permitido la proyección de investigaciones, líneas de pensamiento, artículos científicos y análisis de temas actuales desde perspectivas diversas. Por otra 
parte, ha sido un espacio donde los hechos que se excluyeron en la historia oficial tienen su lugar.

Entre los objetivos nunca se pretendió que el programa dictara pauta de pensamiento o que los contenidos fueran incuestionables. Por el contrario, la producción ha intentado favorecer las discusiones, la investigación, la crítica y la reflexión, individual o grupal.

Por ello, como piloto, como producción prima y modelo, será siempre un antecedente de producción académica para la Cátedra de Historia de la UNED en su afán de promover la divulgación en medios masivos de las discusiones y temáticas académicas, desde una participación interdisciplinaria.

$\mathrm{Su}$ evolución es inevitable no solo por las lecciones aprendidas en 6 años de producción,sino por los cambios en los públicos, en los canales de distribución y hasta en la tecnología.

No obstante, Historias Paralelas es el proyecto radiofónico de comunicación de la Cátedra de Historia de la UNED que ha cumplido el rol de divulgar; explicándolo en palabras de Eduardo Galeano, ha sido una de esas «bocas del tiempo (que) cuentan el viaje» ${ }^{3}$.

\section{ABSTRACT}

\section{Parallel Histories: Histories from Yesterday and Today}

Parallel histories is a radio show created as a pilot program to spread academic contents which allow the observation of current facts from a historic perspective and historic events that impact our present. This experience of a multidisciplinary work, turned into a communication project of academic tasks which goes beyond university classrooms.

Key words: radio show, academia, history, outreach, communication.

\section{RÉSUMÉ}

\section{Histoires parallèles: histoires d'hier et d'aujourd'hui}

Histoires Parallèles est une émission radiophonique crée comme un projet pilote afin de diffuser des contenus académiques qui permettent l'observation de faits actuels dès la perspective historique ou d'événements de l'histoire à partir d'une approche d'impact dans notre présent. L'expérience du travail interdisciplinaire est devenue un projet de communication des activités académiques au-delà des salles universitaires.

Mots-clés: Production radiophonique, académie, histoire, divulgation, communication.

\section{Bibliografía}

Galeano Eduardo. Bocas del Tiempo. Madrid: Siglo XXI de Editores España, 2004.

3. Galeano, Bocas del Tiempo, 4 . 